\title{
INTIMAMENTE PUBLICITADOS: O DIREITO À PRIVACIDADE DAS CELEBRIDADES NA SOCIEDADE CONTEMPORÂNEA
}

PRIVATELY LIVES IN THE MEDIA: CELEBRITIES' RIGHT TO PRIVACY IN CONTEMPORARY SOCIETY

INTIMMAMENTE PUBLICADO: EL DERECHO A LA PRIVACIDAD DE LAS CELEBRIDADES EN LA SOCIEDAD CONTEMPORÁNEA

Luis Carlos Cancellier de Olivo'

Mikhail Vieira Cancelier de Olivo²

1 Professor Associado II do Curso de Direito da Universidade Federal de Santa Catarina. Diretor do Centro de Ciências Jurídicas da UFSC. luis.cancellier@ufsc.br

2 Professor substituto de Direito Civil na Universidade Federal de Santa Cataria (UFSC). Doutorando em direito pelo Programa de Pós-Graduação em Direito da Universidade Federal de Santa Catarina (PPGD/ UFSC). Mestre em Direito e Relações Internacionais pelo Programa de Pós-Graduação em Direito da Universidade Federal de Santa Catarina (PPGD/UFSC). mikhail.cancelier@ufsc.br. 
Resumo: $\mathrm{O}$ art. 20 do Código Civil de 2002 prevê que, salvo se autorizadas, ou se necessárias à administração da justiça ou à manutenção da ordem pública, a divulgação de escritos, a transmissão da palavra ou a publicação, a exposição ou a utilização da imagem de uma pessoa poderão ser proibidas, a seu requerimento e sem prejuízo da indenização que couber, se lhe atingirem a honra, a boa fama ou a respeitabilidade, ou se se destinarem a fins comerciais. Tal necessidade de autorização prévia foi posta em cheque na ADI 4815, julgada em junho desde ano pelo STF. Este artigo busca trabalhar o exercício do direito à privacidade na atualidade e problematiza o tema por meio da discussão acerca da privacidade das pessoas famosas. Exemplo que popularizou a questão, o posicionamento do grupo Procure Saber sobre a necessidade de autorização prévia para a comercialização de biografias será aqui analisado, assim como o voto da Ministra Cármen Lúcia Antunes Rocha, Relatora da referida ADI.

Palavras-chave: Direito à privacidade. Direito à liberdade de expressão. Censura. STF.

Abstract: Article 20 of the 2002 Brazilian Civil Code states that except as authorized or necessary to the administration of justice or to maintain public order, the disclosure of written text, the transmission of the words, or the publication, display or use of the image of a person may be prohibited, at their request and subject to compensation where applicable, if they affect that person's honor, good name or reputation, or if they are intended for commercial purposes. Such need for prior authorization was challenged by the $A D I$ (Direct Action of Unconstitutionality) 4815, but upheld in June of this year by the Supreme Court. This article analyzes the exercise of the right to privacy today, investigating the issue through a discussion on the privacy of celebrities. An example that has brought this issue under the spotlight - the critical positioning of the Procure Saber Group (which defends the need for prior authorization for the marketing of biographies) - is analyzed here, as well as the vote of Cármen Lúcia Antune Rocha, the Rapporteur of the abovementioned ADI. 
Keywords: Right to privacy. Right to freedom of expression. Censorship. The Supreme Court.

Resumen: El art. 20 del Código Civil de 2002 prevé que, salvo si autorizadas o si necesarias a la administración de la justicia o a la manutención del orden público, la divulgación de escritos, la transmisión de la palabra o la publicación, la exposición o la utilización de la imagen de una persona podrán ser prohibidas, a su solicitud y sin perjuicio de la indemnización que corresponda, si es afectada la honra, la buena fama o la respetabilidad, o si se destina a fines comerciales. Tal necesidad de autorización previa fue puesta en jaque en la ADI 4815, juzgada en junio de ese año por el STF. Este artículo busca trabajar el ejercicio del derecho a la privacidad en la actualidad y problematiza el tema por medio de la discusión acerca de la privacidad de las personas famosas. Un ejemplo que popularizó la cuestión y será analizado aquí es el posicionamiento del grupo Procure Saber sobre la necesidad de autorización previa para la comercialización de biografías, así como el voto de la Ministra Cármen Lúcia Antunes Rocha, Relatora de la referida ADI.

Palabras clave: Derecho a la privacidad. Derecho a la libertad de expresión. Censura. STF.

\section{INTRODUÇÃO}

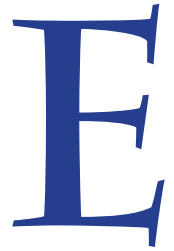

m sua análise da obra de Hannah Arendt, Celso Lafer³, dentre outros pontos, destaca a diferenciação entre os espaços público e privado desenvolvida pela autora. Lafer demonstra que Arendt frisa que o privado deve ser respeitado, já que nem tudo o que se oculta representa, necessariamente, algo em algum nível condenável ou reprovável. Eventualmente - e frequentemente - há aspectos da personalidade, individual ou coletiva, que podem não ser mostrados. Mais do que isso "as grandes forças da vida íntima 3 LAFER, Celso. A reconstrução dos direitos humanos: um diálogo com o pensamento de Hannah Arendt. São Paulo: Companhia das Letras, 1988. p.261;271. 
têm uma existência válida apenas na penumbra"4.

Para Arendt ${ }^{5}$, o público é comum - tanto no sentido de espaço comum quanto no sentido de visto e ouvido por todos - , aproximando-se da ideia de igualdade entre as pessoas; o privado é exclusivo, ressaltando as diferenças. Dentro da esfera privada, cada um escolhe com quem quer e como deseja se relacionar com o mundo e tal escolha é "afetada pelo impacto de uma pessoa em sua singularidade, sua diferença em relação a todas as pessoas que conhecemos"6.

Uma existência vivida inteiramente em público, na presença de outros, torna-se, como diríamos, superficial. Retém a sua visibilidade, mas perde a qualidade resultante de vir à tona a apertar de um terreno mais sóbrio, terrenom este que deve permanecer oculto a fim de não perder sua profundidade num sentido muito real e não subjetivo. $O$ único modo eficaz de garantir a sombra do que deve ser escondido contra a luz da publicidade é a propriedade privada - um lugar só nosso, no qual podemos nos esconder.

Lafer $^{8}$ nota, ainda, que segundo Arendt, o privado é essencial à defesa do público, que acaba sendo ferido quando aquilo que deve ficar restrito ao íntimo invade seu espaço, banalizando-o. A distorção desses ambientes, que pode ser enxergada na excessiva publicização da privacidade, poderia, segundo a autora, degenerar num 'estado totalitário de natureza'. Talvez dentro de certa perspectiva, tenhamos chegado lá.

Nesse sentido, é facilmente notável que a área da privacidade acabou transformando-se num lugar de encarceramento, "sendo o dono do espaço privado condenado e sentenciado a padecer expiando os próprios erros" conclusão de que, hoje, a relação entre o indivíduo e a sua privacidade está abalada. Não só vivemos um momento em que a privacidade é constantemente violada

4 LAFER, Celso. A reconstrução dos direitos humanos: um diálogo com o pensamento de Hannah Arendt. p.261.

5 ARENDT, Hannah. A condição humana. Tradução de Roberto Raposo. 10. ed. Rio de Janeiro: Forense Universitária, 2005. p. 60-62.

6 LAFER, Celso. A reconstrução dos direitos humanos: um diálogo com o pensamento de Hannah Arendt. p.267-268.

7 ARENDT, Hannah. A condição humana. p.81.

8 LAFER, Celso. A reconstrução dos direitos humanos: um diálogo com o pensamento de Hannah Arendt. , p.271.

9 BAUMAN, Zygmunt. Vigilância líquida: diálogos com David Lyon. Tradução de Carlos Alberto Medeiros. Rio de Janeiro: Jorge Zahar Editor, 2014. p.55. 
pelo "outro", como, nós mesmo, de forma deliberada, "submetemos à matança nossos direitos de privacidade por vontade própria"10. Ser "privado" é mal visto e tentar impedir que terceiros tenham acesso àquilo que consideramos de cunho estritamente pessoal é tachado, com bastante frequência, de censura.

Seguindo por esse caminho, Bauman"11 acredita que "o anonimato já está em processo e auto-erosão no Facebook e em outras mídias sociais. O privado é público, é algo a ser celebrado e consumido tanto por incontáveis 'amigos' quanto por 'usuários'casuais." Para ou autor, abrimos os braços à coletivização do privado por vontade própria em troca da "alegria de ser notado"12. Por outro lado, mas dentro desse mesmo movimento, a sociedade contemporânea implode a esfera privada, frequentemente impossibilitando ao indivíduo o alívio de seu lar privativo, "no qual antes ele se sentia resguardado contra o mundo e onde, de qualquer forma, até mesmo os que eram excluídos do mundo podiam encontrarIhe o substituto no calor do lar e na limitada realidade da vida em família"13.

Assim, além de, comojá levantado, optarmos, conforme as nossas necessidades, por fornecer nossas informações pessoais e alimentarmos patologicamente todo o tipo de redes sociais, temos, à nossa revelia e independente de qualquer autorização, nossa vida invadida por programas de coleta de dados que não nos permitem nenhuma forma de controle e reação. Tal comportamento invasivo tornou-se rotineiro. Diariamente, temos, conscientemente, nossa privacidade violada nos mais diversos níveis e não nos damos conta que, com esse comportamento, rejeitamos um componente essencial da formação da pessoa humana, que "define propriamente o que é um indivíduo - quais suas fronteiras com os demais, qual seu grau de interação e comunicação com seus conhecidos, seus familiares e todos os demais" ${ }^{\prime 14}$.

Diante de tal realidade, este artigo busca desenvolver a tema do direito à privacidade contemporânea e, nesse intuito, optamos por trabalhar com o 10 BAUMAN, Zygmunt. Vigilância líquida: diálogos com David Lyon. p.42.

11 BAUMAN, Zygmunt. Vigilância líquida: diálogos com David Lyon. p.32.

12 BAUMAN, Zygmunt. Vigilância líquida: diálogos com David Lyon. p.47.

13 ARENDT, Hannah. A condição humana. p.68-69.

14 DONEDA, Danilo. Privacidade, vida privada e intimidade no ordenamento jurídico brasileiro: Da emergência de uma revisão conceitual e da tutela de dados pessoais. 2008. Disponível em: <http://www.ambitojuridico.com. br/site/index.php?n_link=revista_artigos_leitura\&artigo_id=2460>. Acesso em: 03 maio 2015. 
recorte da privacidade das chamadas "pessoas públicas". Ilustrando o assunto, o artigo estuda o "Caso Procure Saber", que levantou a questão das biografias não autorizadas de celebridades. Na mesma seara, analisaremos o voto da Senhora Ministra Cármen Lúcia, Relatora da Ação Direta de Inconstitucionalidade 4.815, ajuizada pela Associação Nacional dos Editores de Livros (ANEL) em 5 de julho de 2012 e julgada pelo Supremo Tribunal Federal no dia 10 de junho de 2015.

\section{PROCURE ENTENDER}

Constantemente noticiadas à exaustão, as pessoas famosas acabam, deliberada ou impositivamente, lidando de uma forma muito especial com a própria privacidade. Em 2013 a questão ganhou destaque em virtude do posicionamento assumido pelo "Procure Saber", - grupo formado por importantes nomes da música brasileira, como Caetano Veloso, Chico Buarque e Gilberto Gil - que defendeu a necessidade de autorização prévia, para a comercialização de biografias ${ }^{15}$.

Em outubro daquele ano, a então presidente do Procure Saber, Paula Lavigne, enfatizou que o grupo não via problemas na publicação das biografias, mas na comercialização sem autorização. Ainda segundo Lavigne, os fundamentos da liberdade de expressão ou do acesso à informação seriam formas de justificar o lucro com a vida alheia ${ }^{16}$. Também sobre o assunto, o cantor Djavan declarou que "a liberdade de expressão pode causar injustiças" já que "editores e biógrafos ganham fortunas enquanto aos biografados resta o ônus do sofrimento e da indignação". A Associação Nacional de Editores de Livros, por outro lado, declarou à época que a necessidade de autorização prévia ensejaria censura, ferindo a liberdade de expressão e o direito à informação.

A imprensa, de maneira geral, foi impiedosa. As críticas foram desde comparações

15 Após debates acirrados entre o grupo, a imprensa e os representantes das editoras, o grupo optou por não levar adiante a discussão, se dedicando principalmente a questões relacionadas aos direitos de autor. Disponível em: <http://g1.globo.com/musica/noticia/2014/09/caetano-veloso-diz-que-polemicadas-biografias-traumatizou-procure-saber.html>. Acesso em: 28 maio 2015.

16 GRAGNANI, Juliana. Gil e Caetano se juntam a Roberto Carlos contra biografias não autorizadas. Folha de São Paulo. Disponível em: <http://www1.folha.uol.com.br/ilustrada/2013/10/ 1352167-gil-e-caetano-se-juntam-aroberto-carlos-contra-biografias-nao-autorizadas.shtml>. Acesso em: 28 maio 2015. 
com associações racistas e homofóbicas ${ }^{17}$, até a quase unanime classificação dos membros do Procure Saber como censores. Em reportagem, dramaticamente intitulada "Página infeliz da nossa história: Gilberto Gil, Roberto Carlos, Chico Buarque e Caetano Veloso dizem querer resguardar a privacidade, mas as propostas do grupo resumem-se a apenas uma infame palavra: censura", Jerônimo Teixeira ${ }^{18}$ disse que o que estava em jogo no debate era o democrático princípio da liberdade de expressão; sem poupar críticas aos artistas, o jornalista escreveu:

Embora seja vital para todo e qualquer cidadão, a liberdade expressão deveria ser especialmente cara a quem tem na arte seu ofício, e talvez ainda mais aos músicos da geração que, nos anos 60 e 70, sofreu com a censura do regime militar. No entanto, foram estes que se mobilizaram para solapar esse fundamento do Estado de Direito. No grupo ridiculamente chamado Procure Saber, capitaneado pela hábil empresária Paula Lavigne, estão Chico, Caetano Veloso, Gilberto Gil, Djavan, Milton Nascimento, Erasmo Carlos e Roberto Carlos. ${ }^{19}$

Teixeira ${ }^{20}$ também direcionou suas ponderações ao Código Civil de 2002:

Pela letra fria dessa lei, toda biografia precisaria ser autorizada previamente pelo biógrafo ou por seus herdeiros. [...]. A lei que chancela a censura, porém, não pode se sobrepor à Constituição. Não se pode instituir a censura prévia no Brasil por meio de uma lei ordinária, quando a própria Constituição, em seu parágrafo IX (sic) do artigo $5^{\circ}$ determina: [...].

Precursor das discussões, o então Projeto de Lei n. 393/2011, de autoria do deputado Newton Lima (PT/SP), propunha a alteração do art. 20 do Código Civil de 2002. Originalmente, aprovada a modificação, o parágrafo único seria renumerado para $\S 1^{\circ}$, sendo adicionado um $\S 2^{\circ}$, com o seguinte teor:

17 GRAGNANI, Juliana. Grupo que tentou modificar a Lei Áurea quer manter censura a biografias. Folha de São Paulo. Disponível em: < http://www1.folha.uol.com.br/ilustrada/2013/11/1373580-grupo-que-tentou-modificar-leiaurea-quer-manter-censura-a-biografias.shtml>. Acesso em: 28 maio 2015.

18 TEIXEIRA, Jerônimo. Página infeliz da nossa história: Gilberto Gil, Roberto Carlos, Chico Buarque e Caetano Veloso dizem que querem resguardar a privacidade - mas as propostas do grupo resumem-se a apenas uma infame palavra: censura. Revista Veja, São Paulo, p.82-87, 23 de outubro de 2013. p.82-83.

19 TEIXEIRA, Jerônimo. Página infeliz da nossa história: Gilberto Gil, Roberto Carlos, Chico Buarque e Caetano Veloso dizem que querem resguardar a privacidade - mas as propostas do grupo resumem-se a apenas uma infame palavra: censura. p.84.

20 TEIXEIRA, Jerônimo. Página infeliz da nossa história: Gilberto Gil, Roberto Carlos, Chico Buarque e Caetano Veloso dizem que querem resguardar a privacidade - mas as propostas do grupo resumem-se a apenas uma infame palavra: censura. p.85;86. 
$\S 2^{\circ}$ A mera ausência de autorização não impede a divulgação de imagens, escritos e informações com finalidade biográfica de pessoa cuja trajetória pessoal, artística ou profissional tenha dimensão pública ou esteja inserida em acontecimentos de interesse da coletividade.

Após sofrer algumas emendas, o projeto foi aprovado pela Câmara e enviado para o Senado, onde passou a ser identificado como PLC n. 42/2014 e encontrase em tramitação. Nos termos do referido PLC, o art. 20 do CC/2002 passaria a contar com três parágrafos. $\mathrm{O} \$ 1^{\circ}$, a exemplo do projeto inicial, repetiria o atual parágrafo único, sendo transcrita a seguir a redação dos $\S \S 2^{\circ}$ e $3^{\circ}$ :

$\S 2^{\circ} \mathrm{A}$ ausência de autorização não impede a divulgação de imagens, escritos e informações com finalidade biográfica de pessoa cuja trajetória pessoal, artística ou profissional tenha dimensão pública ou que esteja inserida em acontecimentos de interesse da coletividade.

§ $30 \mathrm{Na}$ hipótese do § 20, a pessoa que se sentir atingida em sua honra, boa fama ou respeitabilidade poderá requerer, mediante o procedimento previsto na Lei no 9.099, de 26 de setembro de 1995, a exclusão de trecho que the for ofensivo em edição futura da obra, sem prejuízo da indenização e da ação penal pertinentes, sujeitas essas ao procedimento próprio.

Assim, numa primeira leitura, o dispositivo em tramitação se aproxima da opinião do já citado jornalista, que acredita que "no tangente a figuras públicas políticas, autoridades, artistas —, a liberdade de biografar não pode ser tolhida ${ }^{21}$. Permitimos-nos discordar.

\section{PÚBLICAS, PORÉM PRIVADAS}

No final do Século XIX, alguns jornalistas invadiram a câmara funerária do Príncipe Otto von Bismarck (personagem de extremo apelo popular na época) e fotografaram seu corpo, objetivando vender as imagens obtidas. Os herdeiros do falecido monarca "processaram os fotógrafos e obtiveram uma injunção para

21 TEIXEIRA, Jerônimo. Página infeliz da nossa história: Gilberto Gil, Roberto Carlos, Chico Buarque e Caetano Veloso dizem que querem resguardar a privacidade - mas as propostas do grupo resumem-se a apenas uma infame palavra: censura. p.86. 
impedir a divulgação das imagens, além da apreensão das chapas, dos negativos e das impressões" 22 . Diante desse fato, percebe-se que o desrespeito aos direitos da personalidade das ditas "celebridades" não é novidade; e mais, se é verdade que as inovações tecnológicas atingem à privacidade de todos, em maior ou menor nível, esse nicho da população vem de forma cada vez mais brusca sendo afetada pelas novas definições de público e privado.

Essas pessoas, em virtude da profissão que exercem, acabam levantando o interesse de boa parcela da população sobre suas vidas privadas e independentemente do motivo que as tornaram célebres, são constantemente expostas como animais em zoológicos, movimentando toda uma indústria que sobrevive, basicamente, da invasão à privacidade. É inegável o fato de que boa parte dessas celebridades comemora tal interesse obsessivo, até mesmo incentivando essa "invasão"; no entanto seria equivocado dizer que todos que assumem a característica de "pessoas públicas" automaticamente optam por compartilhar tudo com todos.

Rodrigues Junior ${ }^{23}$, ao abordar o tema, define que há duas formas de classificação das celebridades. Existiria, segundo o autor, as celebridades em sentido estrito, representadas pelo grupo dos artistas, músicos e jogadores de futebol, por exemplo; e as celebridades em sentido amplo, que, além daquelas, englobaria também a classe política. Sobre elas, ele argumenta que:

Essas pessoas têm em comum algumas características: a) a aquisição de vantagens políticas ou econômicas advindas de sua exposição ao público, mesmo em níveis que normalmente se revelariam invasivos de sua vida privada e de sua intimidade, bem assim de sua imagem; b) a notoriedade do cargo que ocupam, seu poder de influência nos destinos políticos, econômicos, culturais ou comportamentais são fatores que determinam interesse dos meios de comunicação superiormente intenso sobre seu procedimento público ou privado; c) a assunção dos riscos pela superexposição, como algo inerente à atividade exercida. ${ }^{24}$

22 RODRIGUES JUNIOR, Otavio Luiz. Do príncipe Bismarck à princesa Carolina de Mônaco: vida privada de pessoas célebres e as liberdades comunicativas no direito civil. In: CASSETTARI, Christiano (Org.). 10 anos de vigência do código civil brasileiro de 2002: estudos em homenagem ao professor Carlos Alberto Dabus Maluf. São Paulo: Saraiva, 2013. p.115-116.

23 RODRIGUES JUNIOR, Otavio Luiz. Do príncipe Bismarck à princesa Carolina de Mônaco: vida privada de pessoas célebres e as liberdades comunicativas no direito civil. p.114.

24 RODRIGUES JUNIOR, Otavio Luiz. Do príncipe Bismarck à princesa Carolina de Mônaco: vida privada 
Dito isso, cabe, em primeiro lugar, definir que concordamos com Schreiber ${ }^{25}$ quando diz que deve ser completamente rejeitada a qualificação de qualquer ser humano como "público", já que "pessoas são privadas por definição", sendo que a "expressão pessoa pública é empregada com o propósito de sugerir que o uso da imagem de celebridades dispensa autorização, pelo simples fato de que vivem de sua exposição na mídia". Também em concordância com o autor, acreditamos que tais pessoas, mais do que terem seus direitos da personalidade protegidos como os de qualquer um, têm reforçada essa proteção, justamente pelo fato de viverem do uso de sua imagem.

Felizmente, após anos de ditadura militar ${ }^{26}$, logramos alcançar um estágio de desenvolvimento tal, no que diz respeito às liberdades individuais, que podemos dizer que vivemos em um país que valoriza amplamente a liberdade de imprensa e o acesso à informação. É justamente embasada nessa liberdade, que a imprensa frequentemente divulga fatos ligados à intimidade de celebridades - em sentido amplo - com a justificativa de informar à população acerca dessas pessoas. $O$ que percebemos, contudo, é que falta ponderação. Nesse sentido, Schreiber ${ }^{27}$ defende que:

O direito incontestável do público à informação limita-se aos aspectos públicos da vida da celebridade [...]. Tudo que traspasse essa fronteira pode possuir, sim, uma utilidade informativa, relacionada à formação do caráter e da personalidade do ídolo, mas tal utilidade deve ser cuidadosamente ponderada em face da proteção à privacidade do retratado.

Fazendo referência à classificação dos grupos de celebridades anteriormente mencionados, Rodrigues Junior ${ }^{28}$ acredita que a liberdade de imprensa "pode ser restringida se a exposição implicar danos econômicos irrazoáveis" naquilo que diz respeito às celebridades em sentido estrito e "se a divulgação da intimidade não se relacionar com o interesse público", aí incluindo a classe política.

de pessoas célebres e as liberdades comunicativas no direito civil. p.114.

25 SCHREIBER, Anderson. Direitos da personalidade. 2. ed. São Paulo: Atlas, 2013. p.111-112.

26 Período que vai de 1964 a 1985. Disponível em: <http://memoriasdaditadura.org.br/>. Acesso em: 23 jun. 2015.

27 SCHREIBER, Anderson. Direitos da personalidade. p.149.

28 RODRIGUES JUNIOR, Otavio Luiz. Do príncipe Bismarck à princesa Carolina de Mônaco: vida privada de pessoas célebres e as liberdades comunicativas no direito civil. p.122. 
Voltando às biografias, a solução não é evidente, sendo fundamental a análise do caso concreto. Nesse sentido, é importante verificar determinados aspectos na obra analisada. Schreiber ${ }^{29}$ nos apresenta alguns desses pontos:

São circunstâncias relevantes: (i) a repercussão emocional do fato sobre o biografado; (ii) a atitude mais ou menos reservada do biografado em relação ao fato; (iii) a importância daquele fato para a formação da personalidade do biografado (e, portanto, a necessidade da sua divulgação no âmbito da biografia); (iv) o eventual envolvimento de terceiros e seu grau de identificação no relato; (v) o formato da apresentação do fato, que pode ser mais ou menos sensacionalista; (vi) os riscos para outros direitos do biografado, como o seu direito à honra [...].

Ou seja, embora medidas restritivas a editoras e seus biógrafos possam gerar algum tipo de inconveniente aos mesmos, é imperioso ter em mente que qualquer pessoa, célebre ou não, tem direito à privacidade, podendo desejar manter em segredo fatos sobre sua vida íntima. Certamente, o movimento de não permitir que determinada obra seja comercializada em função de seu conteúdo, deve ser, de maneira geral, combatido. Contudo, permitir que essa obra, na mesma acepção generalista, circule a despeito da evidente lesão à privacidade que perpetra seria o equivalente à atribuição de "um preço à intimidade do biografado, com efeitos bem mais nefastos do que se pode perceber a princípio"30.

\section{PÚBLICO E PRIVADO: UM MUNDO SEM FRONTEIRAS}

Em breve retrospecto histórico, Hannah Arennt ${ }^{31}$ lembra que, desde o surgimento das cidades-estado estabeleceu-se a distinção entre as esferas pública - a esfera da polis, da política - e privada - a esfera da família -, distinção essa que passou a sofrer importantes alterações com a ascenção do mundo moderno, quando diversas questões antes pertinentes exclusivamente à esfera privada passam a figurar como de interesse "coletivo". Tais mutações impuseram a redefinição das fronteiras entre as esferas até ao ponto em

29 SCHREIBER, Anderson. Direitos da personalidade. p.150.

30 SCHREIBER, Anderson. Direitos da personalidade. p.151.

31 ARENDT, Hannah. A condição humana. p.42-43. 
que chegamos onde ambas se englobam, formatando, por vezes, um grande espaço "público/privado".

Elemento fundamental a essa transformação é a internet, afinal, independentemente do conceito atribuído à privacidade, é possível constatar que ela "sempre foi diretamente condicionada pelo estado da tecnologia em cada época e sociedade" ${ }^{\prime 32}$. A internet, de acordo com Greenwald ${ }^{33}$, já há algum tempo ultrapassou o status de correio ou telefone, abraçando a totalidade do nosso mundo. Nesse espaço, ainda citando o autor, "desenvolvemos e expressamos nossa personalidade e individualidade", sendo "criados e armazenados os dados mais particulares de cada um". Sendo, então, característica exponencial da sociedade contemporânea, é por evidente concluir que essa nova ágora tecnológica interfere diretamente no relacionamento entre sociedade e privacidade.

Tendo tais fatores em vista, Doneda ${ }^{34}$ observa que a proteção "mais adequada para a privacidade não reside mais na garantia de isolamento e segredo, mas sim em uma perspectiva de amplo controle da circulação de informações pessoais". Muito mais do que a indiscrição de um vizinho que, com as luzes apagadas, se demora por mais tempo do que deveria na sua janela observando o que ocorre na casa ao lado, a invasão à privacidade no século XXI diz respeito à informação.

Assim, sendo utilizada a expressão privacidade de forma ampla, temos que ela abrange "hoje, não apenas a proteção à vida íntima do indivíduo, mas também a proteção de seus dados pessoais", podendo ser "definida sinteticamente como o direito ao controle da coleta e da utilização dos próprios dados pessoais" ${ }^{\prime \prime}$.

Conjuntamente, a exemplo de diversos outros direitos fundamentais (como honra e imagem), o legislador classifica o direito à privacidade como direito de personalidade ${ }^{36}$, prevendo-o no art. 21 , o qual define como inviolável a vida privada

32 CELLA, José Renato Gaziero; ROSA, Luana Aparecida dos Santos. Controle social e necessidade de proteção de dados pessoais. In: Revista de Direito Brasileira (RBD). Florianópolis: CONPEDI, 2013, p.216-231.

33 GREENWALD, Gleen. Sem lugar para se esconder. Tradução de Fernanda Abreu. Rio de Janeiro: Sextante, 2014. p.15.

34 DONEDA, Danilo. Considerações iniciais sobre os bancos de dados informatizados e o direito à privacidade. 2000. Disponível em: <http://www.estig.ipbeja.pt/ ac_direito/Consideracoes.pdf>. Acesso em 28 maio 2015.

35 SCHREIBER, Anderson. Direitos da personalidade. p.136-137.

36 "Os direitos de personalidade dão conteúdo essencial à personalidade e por isso são qualificados como direitos essenciais. Sem eles, a personalidade restaria uma 'suscetibilidade irrealizada', destituída de valor concreto. São direitos sem os quais todos os outros direitos subjetivos perderiam todo o interesse 
da pessoa natural. Na realidade, o direito à privacidade pode ser apresentado como exemplo da ciência jurídica contemporânea, "que vem superando o abismo [...] entre direito público e privado para reunificar as duas esferas em torno da unidade constitucional ${ }^{37 "}$.

Tem-se, dessa forma, que a privacidade é direito universal, na medida em que basta a qualidade de pessoa para que seja atribuída ao seu titular; perpétuo, se constituindo com o nascimento da pessoa, extinguindo-se apenas com a sua morte; inato, pois essencial em relação à pessoa; e indisponível ${ }^{38}$, unido ao sujeito originário por um nexo orgânico, que os torna inseparáveis ${ }^{39}$. Cabral ${ }^{40}$ lembra que, no entanto, não se pode transformar o "direito à privacidade num dever de privacidade, havendo possibilidade de os indivíduos exercerem o direito à privacidade de modos diversos, sem que isso implique renúncia ao direito", visto que, por exemplo, alguém que decide "tornar públicos comportamentos geralmente protegidos pela reserva da intimidade da vida privada não está, por esse motivo, a renunciar a esse direito, mais sim a exercê-lo autonomamente de acordo com suas próprias preferências".

para o indivíduo - o que equivale a dizer que, se eles não existissem, a pessoa não existiria como tal." (MAZUR, 2012. p.28).

37 SCHREIBER, Anderson. Direitos da personalidade. p.13.

38 Tratando sobre a irrenunciabilidade dos direitos de personalidade, Anderson Schreiber (2013, p.27) abre o debate acerca da limitação voluntária ao exercício desse direito. Segundo o autor, "tal limitação, derivada da vontade do titular, não deve a toda evidência ser reprimida pela ordem jurídica, porque a vontade individual aí não se opõe, mas se dirige à realização da dignidade humana naquele indivíduo". O autor continua: "a autolimitação ao exercício dos direitos da personalidade deve ser admitida pela ordem jurídica quando atenda genuinamente ao propósito de realização de personalidade de seu titular. Deve, ao contrário, ser repelida sempre que guiada por interesses que não estão própria ou imediatamente voltados à realização da dignidade daquela pessoa".

39 MAZUR, Maurício. A dicotomia entre os direitos de personalidade e os direitos fundamentais. In: FRUET, Gustavo Bonato; MIRANDA, Jorge; RODRIGUES JUNIOR, Otavio Luiz (Org.). Direitos da personalidade. São Paulo: Atlas, 2012. p. 34-35.

40 CABRAL, Marcelo Malizia. A colisão entre os direitos de personalidade e o direito de informação. In: FRUET, Gustavo Bonato; MIRANDA, Jorge; RODRIGUES JUNIOR, Otavio Luiz (Org.). Direitos da personalidade. São Paulo: Atlas, 2012. p.138-139. 


\section{"NÃO ADIANTA CHORAR. SORRIA, VOCÊ ESTÁ SENDO FILMADO. ${ }^{41 "}$}

No ano de 2012, a Associação Nacional dos Editores de Livros (ANEL) ajuizou Ação Direita de Inconstitucionalidade, objetivando "a declaração da inconstitucionalidade parcial, sem redução de texto, dos arts. 20 e 21" da Lei n. 10.406/2002 (Código Civil)". A autora formulou pedido no sentido de que fosse afastado "do ordenamento jurídico brasileiro a necessidade do consentimento da pessoa biografada [...] para a publicação ou veiculação de obras biográficas, literárias ou audiovisuais". Argumentou a autora que os referidos artigos do Código Civil de 2002, na forma em que estão postos, violam "as liberdades de manifestação do pensamento, da atividade intelectual, artística, científica e de comunicação (CF, art. 5o, IV e IX), além do direito difuso da cidadania à informação (art. 50, XIV)"42.

Em voto de valor doutrinário excepcional, a Ministra Cármen Lúcia abordou com metodologia e didática impecáveis os conceitos de direito à liberdade de expressão, censura e privacidade, dentre outros, discorrendo sobre a evolução histórica dos mesmos e suas formas de aplicabilidade contemporâneas. A Ministra julgou procedente a ADI, dando interpretação aos artigos 20 e 21 do CC/2002, conforme a Constituição de 1988, para:

em consonância com os direitos fundamentais à liberdade de pensamento e de sua expressão, de criação artística, produção científica, declarar inexigível o consentimento de pessoa biografada relativamente a obras biográficas literárias ou audiovisuais, sendo por igual desnecessária autorização de pessoas retratadas como coadjuvantes (ou de seus familiares, em caso de pessoas falecidas);

reafirmar o direito à inviolabilidade da intimidade, da privacidade, da honra e da imagem da pessoa, nos termos do inc. $X$ do art. 50 da Constituição da República, cuja transgressão haverá de se reparar mediante indenização. ${ }^{43}$

41 Todos os extratos textuais apresentados nesta seção foram retirados do voto da Senhora Ministra Cármen Lúcia: BRASIL. Supremo Tribunal Federal. Ação direta de inconstitucionalidade 4815 Distrito Federal. Relatora Ministra Cármen Lúcia. 10 de junho de 2015. Disponível em: <http://www.stf.jus.br/ arquivo/cms/noticiaNoticiaStf/anexo/ADI4815relatora.pdf>. Acesso em: 25.04.2016.

42 BRASIL. Supremo Tribunal Federal. Ação Direta de Inconstitucionalidade $\mathbf{n}^{\circ}$ 4815. Relatora: Ministra Carmem Lúcia Antunes Rocha. Origem Distrito Federal. DJe 16.02.2016. Disponível em: http://www.stf.jus. $\mathrm{br} /$ portal/processo/verProcessoAndamento.asp?incidente=4271057. Acesso em: 25.04.2016. p.02-03.

43 BRASIL. Supremo Tribunal Federal. Ação Direta de Inconstitucionalidade $\mathbf{n}^{\circ}$ 4815. Relatora: Ministra 
Segundo Cármen Lúcia, mesmo seguindo a nova interpretação dos dispositivos:

Não se extingue [...] o direito à inviolabilidade da intimidade ou da vida privada. Respeita-se, no direito, o que prevalece no caso posto em juízo, sem juízo prévio de censura nem possibilidade de se afirmar - de menos no direito brasileiro - a censura prévia ou a posteriori, de natureza legislativa, política, administrativa ou judicial, deixandose em relevo e resguardo o que a Constituição fixou como inerente à dignidade humana e a ser solucionado em casos nos quais se patenteie desobediência aos princípios fundamentais do sistema. ${ }^{44}$

A Relatora, ao iniciar seu voto, tomando por base os arts. $5^{\circ}, \mathrm{V}, \mathrm{V}, \mathrm{IX}, \mathrm{X}$ e XIV e 220, da CRFB/88 - em conjunto com os artigos 20 e 21 do CC/2002 -, formula questionamentos acerca desses dispositivos. Assim, pergunta se, numa primeira leitura, (a) seria possível considerar que a necessária autorização do biografado, nos termos do art. 20, sem qualquer tipo de exceção, seria exorbitante, ferindo a liberdade constitucional de outrem, ou se, por outro lado, (b) seriam constitucionais as regras da lei civil, que "desdobram aqueles princípios com realce a direitos individuais, sem conflito substantivo, pelo que poderia ser ultrapassado mantendo-se o espaço de decisão particular do interessado?"45. No decorrer do voto e, sobretudo, em sua conclusão, trabalhando a ponderação e a harmonização dos princípios e preceitos constitucionais, a resposta da Ministra tende a ser positiva para a pergunta "a" e negativa para a pergunta "b". Permitimonos, aqui, tentar oferecer uma perspectiva diversa.

O direito à liberdade de expressão é posto com um dos fundamentos da democracia, como o direito que permite a liberdade de pensar, verdadeiro construtor da história, configurando-se na própria comunicação entre as pessoas ${ }^{46}$.

Carmem Lúcia Antunes Rocha. Origem Distrito Federal. DJe 16.02.2016. Disponível em: http://www.stf.jus. $\mathrm{br} /$ portal/processo/verProcessoAndamento.asp?incidente=4271057. Acesso em: 25.04.2016. p.118-119. Carmem Lúcia Antunes Rocha. Origem Distrito Federal. DJe 16.02.2016. Disponível em: http://www.stf. jus.br/portal/processo/verProcessoAndamento.asp?incidente=4271057. Acesso em: 25.04.2016. p.118. Carmem Lúcia Antunes Rocha. Origem Distrito Federal. DJe 16.02.2016. Disponível em: http://www.stf.jus. $\mathrm{br} /$ portal/processo/verProcessoAndamento.asp?incidente=4271057. Acesso em: 25.04.2016. p.24-25. jus.br/portal/processo/verProcessoAndamento.asp?incidente=4271057. Acesso em: 25.04.2016. p.29. 
Exercitamos para criticar, para denunciar, para contar, para dizer. É essencial à condição humana. Há pouco tempo, nosso Estado cometeu atrocidades com esse direito fundamental, e legislou com o objetivo de sufocá-lo:

DECRETO-LEI No 1.077, DE 26 DE JANEIRO DE 1970

Dispõe sobre a execução do artigo 153 , § $8^{\circ}$, parte final, da Constituição da República Federativa do Brasil. O PRESIDENTE DA REPÚBLICA, usando da atribuição que lhe confere o artigo 55, inciso I da Constituição e

CONSIDERANDO que a Constituição da República, no artigo 153, § $8^{\circ}$ dispõe que não serão toleradas as publicações e exteriorizações contrárias à moral e aos costumes;

CONSIDERANDO que essa norma visa a proteger a instituição da família, preserva-lhe os valôres (sic.) éticos e assegurar a formação sadia e digna da mocidade;

CONSIDERANDO, todavia, que algumas revistas fazem publicações obscenas e canais de televisão executam programas contrários à moral e aos bons costumes;

CONSIDERANDO que se tem generalizado a divulgação de livros que ofendem frontalmente à moral comum;

CONSIDERANDO que tais publicações e exteriorizações estimulam a licença, insinuam o amor livre e ameaçam destruir os valores morais da sociedade Brasileira;

CONSIDERANDO que o emprêgo (sic.) dêsses (sic.) meios de comunicação obedece a um plano subversivo, que põe em risco a segurança nacional.

\section{DECRETA:}

Art. $1^{\circ}$ Não serão toleradas as publicações e exteriorizações contrárias à moral e aos bons costumes quaisquer que sejam os meios de comunicação. 


\section{$[\ldots]$}

Brasília, 26 de janeiro de 1970; $149^{\circ}$ da Independência e $82^{\circ}$ da República.

EMÍLIO G. MÉDICI Alfredo Buzaid ${ }^{47}$

A ditadura militar deixou cicatrizes profundas no Brasil, e é importante que essas marcas permaneçãm, para que não sejam esquecidas. Dentre tantos pavores, a fobia à censura é um dos mais enfatizados. Naquela época, a censura foi praticada pelo Estado, de forma legítima e perversa. Para além do Estado, contudo, também pode haver censura entre particulares. Quando alguém, que não o autor do que se expressa, impossibilita a divulgação dessa expressão, pratica censura. "Pode-se afirmar que se controla o outro. Alguém - o censor - faz-se senhor não apenas da expressão do pensamento ou do sentimento de alguém, mas - o que é mais - controla-se o acervo de informação que se pode passar a outros" ${ }^{48}$.

A censura, nesse formato, deve ser combatida, e assim o é. A postura do constituinte, nesse sentido, foi precisa. Não apenas inseriu o seu repúdio no rol dos direitos fundamentais (art. 50, IX) como dedicou todo um artigo (220) a evitar sua manifestação. Assim, vivemos, hoje, em um país com ampla liberdade de informação, com imprensa livre, onde todos podem dizer o que pensam o ouvir o que querem. É preciso, contudo, despir a expressão de seu manto totalitário, e trabalhá-la de sob outras perspectivas. Se nas novelas e séries televisivas percebemos que a figura do vilão como personagem representante do mau e do mocinho como aquele que representa o bem não funcionam mais ${ }^{49}$, no Direito, temos que ter a mesma postura com alguns conceitos. Por exemplo: discriminar é reprovável; é ilícito; é imoral. Ações afirmativas, contudo, "discriminam" de forma benéfica.

47 BRASIL. Supremo Tribunal Federal. Ação Direta de Inconstitucionalidade $n^{\circ}$ 4815. Relatora: Ministra Carmem Lúcia Antunes Rocha. Origem Distrito Federal. DJe 16.02.2016. Disponível em: http://www.stf. jus.br/portal/processo/verProcessoAndamento.asp?incidente=4271057. Acesso em: 25.04.2016. p.43.

BRASIL. Supremo Tribunal Federal. Ação Direta de Inconstitucionalidade $\mathbf{n}^{\circ}$ 4815. Relatora: Ministra Carmem Lúcia Antunes Rocha. Origem Distrito Federal. DJe 16.02.2016. Disponível em: http://www.stf. jus.br/portal/processo/verProcessoAndamento.asp?incidente=4271057. Acesso em: 25.04.2016. p.45. 
A palavra censura é definida pelo dicionário Houaiss, também, como a "restrição à publicitação de informações; juízo desfavorável; desaprovação, discordância". Ora, quando um processo corre em segredo de justiça, o conteúdo presente nele é "censurado"; só diz respeito aos envolvidos e a ninguém mais. Quando o rosto de um menor é desfocado pela produção de um jornal que transmite sua entrevista, há "censura" com finalidade protetiva desse menor. Quando determinado filme só recebe aprovação para ser veiculado depois de determinado horário, há "censura" daquele conteúdo à determinada parcela da população.

Com isso, quer-se dizer que é evidente que a censura repressora, que tolhe e que impossibilita o público de ter acesso a informações importantes à formação de sua opinião é atroz e condenável. Tentar fazer com que determinada informação de cunho estritamente individual e íntimo (informação essa que não se configura como importante à vida de quem quer que seja salvo a de seu detentor), contudo, não parece o mesmo movimento, pelo menos em intenção.

Disse-se no voto que a "vida do outro há de ser preservada", que "a curiosidade de todos há de ser satisfeita" e que cabe ao biógrafo cumprir o segundo papel; que é justamente esse "espaço de quase segredo que parece mais interessar ao pesquisador, ao biógrafo, que atende necessidades da história e também à curiosidade das pessoas" 50 . Dando máxima vênia a tal posicionamento, acreditamos que a tomada desse posicionamento como regra, em nome da ampla, geral e irrestrita liberdade de informação, leva, sim, ao contrário do que se prescreve, à extinção do direito à privacidade.

Restringir a informação é censurar, mas acabar com o ambiente privado o é, também. Uma realidade na qual não haja como impedir a invasão à privacidade é tão opressora quanto àquela dominada pela censura autoritária. Se tomarmos como exemplo a sociedade ficcional da obra 1984, de George Orwell, temos uma comunidade desprovida do íntimo e do privado; é uma sociedade altamente censurada. Há censura do espaço, há censura da liberdade, há censura da individualidade, há censura do segredo.

50 BRASIL. Supremo Tribunal Federal. Ação Direta de Inconstitucionalidade $n^{\circ}$ 4815. Relatora: Ministra Carmem Lúcia Antunes Rocha. Origem Distrito Federal. DJe 16.02.2016. Disponível em: http://www.stf.jus. br/portal/processo/verProcessoAndamento.asp?incidente=4271057. Acesso em: 25.04.2016. p.98-99. 
Sim, temos meios de nos defender do abuso do direito à liberdade de expressão:

O dever de respeito ao direito do outro conduz ao de responder nos casos em que, mesmo no exercício de direito legitimamente posto no sistema jurídico, se exorbite causando dano a terceiro. [...]. Quem informa e divulga informação responde por eventual excesso, apurado por critério que demonstre dano decorrente da circunstância de ter sido ultrapassada esfera garantida de direito do outro. A informação, a exposição, a divulgação de dado pode gerar dano como qualquer outro agir humano. [...] A responsabilidade constitucionalmente estabelecida - corolário do Estado Democrático de Direito, no qual direitos e responsabilidades compõem-se para a convivência harmoniosa na polis - não se afasta por ser o autor da ação danosa titular dos direitos fundamentais, no exercício dos quais terá exorbitado a intervir na esfera de direitos de outrem e que têm igual natureza e idêntico resguardo. ${ }^{51}$

No entanto, é imperioso o questionamento acerca da efetiva reparação que a mera indenização, por maior que seja, produz. Por vezes, a honra, a imagem (também direitos fundamentais tutelados pela nossa Constituição) ou a família não resistem à informação divulgada, seja ela verdadeira ou não. Sim, como bem ressalta a Ministra Cármen Lúcia, "temem-se enganos e fraudes". Mas, ao contrário do defendido pela Relatora, nem sempre tais enganos são de possível reparação. A Ministra acredita que o risco é compreensível e concreto, mas que viver é arriscar. Define que erros "corrigem-se segundo o direito, não é se abatendo liberdades conquistadas que se segue na melhor trilha democrática traçada com duras lutas" 52 .

Ora, a liberdade de informação ou o direito à liberdade de expressão são conquistas advindas de árduas batalhas (físicas e ideológicas) e merecem toda a proteção possível. O mesmo podemos dizer do direito à privacidade. Deixar o mesmo à mercê das desventuras da vida, no sentido de aceitar que sim, viver é arriscar e a privacidade deve se submeter ao risco da invasão, é desmerecer um 51 BRASIL. Supremo Tribunal Federal. Ação Direta de Inconstitucionalidade $n^{\circ}$ 4815. Relatora: Ministra Carmem Lúcia Antunes Rocha. Origem Distrito Federal. DJe 16.02.2016. Disponível em: http://www.stf.jus. $\mathrm{br} /$ portal/processo/verProcessoAndamento.asp?incidente=4271057. Acesso em: 25.04.2016. p.66; 68 .

BRASIL. Supremo Tribunal Federal. Ação Direta de Inconstitucionalidade $\mathbf{n}^{\circ} \mathbf{4 8 1 5}$. Relatora: Ministra Carmem Lúcia Antunes Rocha. Origem Distrito Federal. DJe 16.02.2016. Disponível em: http://www. stf.jus.br/portal/processo/verProcessoAndamento.asp?incidente=4271057. Acesso em: 25.04.2016. p.107. 
direito que é - natural e positivamente - tão fundamental quanto os demais. Não é suficiente para o seu efetivo exercício a simples defesa-posterior da privacidade (indenizável monetariamente), é preciso ser proativo e impedir a sua violação. É preciso, quando possível, não permitir que o dano ocorra.

Cármen Lúcia é categórica: "Não adianta chorar. Sorria, você está sendo filmado ${ }^{53}$. De fato, vivemos em uma sociedade que exige o compartilhamento. A divulgação de informações pessoais é a regra. Restringir o acesso ao que quer que seja é uma atitude quase condenável. Essa é a realidade. Adaptamo-nos a ela socialmente e precisamos trabalhar o Direito para também promover uma adaptação jurídica, que nos proporcione mais segurança aos "riscos próprios do viver" $^{\prime \prime 4}$. Não adiante chorar e tão pouco se resignar. No embate entre o direito à liberdade de expressão e o direito à privacidade, a resposta não pode ser única, e tornar desnecessária a autorização prévia prevista no art. 20 do Código Civil de 2002 é, no mínimo, querer generalizar um problema não generalizável.

Com relação às pessoas famosas, a Ministra parece acreditar que essas, em virtude de sua profissão, subscrevem termo tácito de renúncia à privacidade e à intimidade:

Vem dos Antigos que aquele que não se quer expor ao público há de se manter nos umbrais da porta de casa, em cujo espaço, naquele período histórico, era sinônimo de segredo; [...] Quem busca a luz não há de exigir espaço intocado de sombra [...] A notoriedade tem preço: ele é fixado pela extensão da fama. E essa é quase sempre buscada. $E$ quando não é, mas ainda assim é obtida, cobra pedágio: é o bilhete do reconhecimento público que se traduz em exposição do espaço particular, no qual querem adentrar todos.

Verdade é que o exercício da privacidade sofre uma série de autolimitações; as redes sociais e os reality shows são a prova disso. No entanto, o direito à privacidade é irrenunciável, independentemente da profissão do seu titular. É

53 BRASIL. Supremo Tribunal Federal. Ação Direta de Inconstitucionalidade $\mathbf{n}^{\circ}$ 4815. Relatora: Ministra Carmem Lúcia Antunes Rocha. Origem Distrito Federal. DJe 16.02.2016. Disponível em: http://www.stf. jus.br/portal/processo/verProcessoAndamento.asp?incidente=4271057. Acesso em: 25.04.2016. p.96.

54 BRASIL. Supremo Tribunal Federal. Ação Direta de Inconstitucionalidade $\mathbf{n}^{\circ} \mathbf{4 8 1 5}$. Relatora: Ministra Carmem Lúcia Antunes Rocha. Origem Distrito Federal. DJe 16.02.2016. Disponível em: http://www. stf.jus.br/portal/processo/verProcessoAndamento.asp?incidente=4271057. Acesso em: 25.04.2016. p.107. 
evidente que, ao exercer ofício público, a pessoa terá que lidar com assédios e ingerências próprios do trabalho que escolheu. Além disso, é implícita às atividades laborais que tornam seus trabalhadores célebres, a publicitação de toda uma gama informativa acerca dessas pessoas. A liberdade de acesso a tais informações, contudo, deve ser restrita aos seus aspectos públicos, de fato. Retirar o direito à privacidade dessas pessoas e permitir que qualquer um escreva qualquer coisa (desde que indenize o objeto da escrita posteriormente) sobre elas e ainda lucre com isso, a nosso ver, é agir de forma tão autoritária e indigna quanto os censores do regime militar.

\section{CONSIDERAÇÕES FINAIS}

Conforme já ressaltado, o CC/2002 exige autorização da pessoa sobre a qual escrevemos para que os escritos sejam utilizados com finalidade comercial ${ }^{55}$. Além disso, a mesma lei define como inviolável ${ }^{56}$ a vida privada da pessoa natural. Fazemos coro aos doutrinadores que demandam a atualização de tais dispositivos.

Não apenas no que diz respeito ao direito à privacidade, mas todo o capítulo que trata do direito da personalidade demanda com urgência maior proximidade com a realidade da sociedade contemporânea. No que diz respeito à privacidade, contudo, tal urgência é gritante.

Como já dissemos, vivemos um momento de mudança comportamental no que diz respeito à nossa relação com o privado. $O$ mundo digital trouxe uma nova forma de interação interpessoal e, junto com ela, a velocidade com que as informações circulam cresceram exponencialmente.

Se por um lado alimentamos constantemente - e de forma deliberada - os bancos de dados virtuais, por outro, mesmo sem nos darmos conta, nossos passos são

55 Art. 20. Salvo se autorizadas, ou se necessárias à administração da justiça ou à manutenção da ordem pública, a divulgação de escritos, a transmissão da palavra, ou a publicação, a exposição ou a utilização da imagem de uma pessoa poderão ser proibidas, a seu requerimento e sem prejuízo da indenização que couber, se the atingirem a honra, a boa fama ou a respeitabilidade, ou se se destinarem a fins comerciais.

56 Art. 21. A vida privada da pessoa natural é inviolável, e o juiz, a requerimento do interessado, adotará as providências necessárias para impedir ou fazer cessar ato contrário a esta norma. 
com a mesma frequência monitorados. Basta uma busca sobre passagens aéreas para determinado destino que, imediatamente, somos bombardeados em todos os demais sites que visitamos com publicidades que fazem referência ao mesmo local.

Aí reside a necessidade de adequação legislativa. Definir a privacidade como "inviolável", na realidade tecnológica atual, é utópico. É preciso que a proteção à privacidade se torne mais efetiva e, para isso, é preciso entender o que é a privacidade nos dias de hoje.

O voto proferido pela Ministra Relatora Cármen Lúcia, e seguido pelos demais membros do Supremo Tribunal Federal, alterou a interpretação dada aos artigos 20 e 21 do Código Civil, não mais exigindo a autorização prévia para a publicação de biografias. Tal decisão altera o entendimento, mas não resolve o problema.

Definir os artigos do Código Civil de 2002 que regulamentam a privacidade como dispositivos chanceladores da censura, comparando-os aos textos normativos restritivos do regime militar, não só é inadequado como é desrespeitoso àqueles que de fato sofreram com a real censura dos tempos da ditadura.

O código em momento algum proíbe a divulgação dos escritos, tão somente exige que, para que sejam comercializados - ou seja, gerem lucro para alguém —, é necessário que o "objeto" da obra (ou seus herdeiros) autorize a transação comercial. Além disso, a lei protege a honra e a imagem do noticiado/biografado, possibilitando indenização por danos morais caso tais direitos sejam lesionados.

Privar terceiros de fatos estritamente pessoais que dizem respeito somente aos que os vivenciaram não é censurar, é exercer o direito fundamental à privacidade.

Direito este expresso na $\mathrm{CRFB} / 88$, no art. 50, ao lado da manifestação do pensamento, da livre expressão da atividade intelectual e do acesso à informação. Todos direitos igualmente fundamentais; sem qualquer hierarquia ou privilégio. Por vezes, há que se privilegiar o acesso à informação: se um político é flagrado praticando ato de corrupção, por exemplo, é de se esperar que os jornais do país noticiem tal fato, em benefício da população. Se o mesmo político, todavia, é flagrado traindo sua esposa, num outro exemplo, não há qualquer tipo de 
interesse público nessa informação, o assunto diz respeito única e exclusivamente ao casal; vigora a privacidade.

O mesmo vale para as celebridades. Há fatos públicos e notórios sobre a vida dessas pessoas que normalmente fazem referência às suas carreiras ou a questões divulgadas por elas mesmas. A divulgação dessas informações não atinge ninguém. No entanto há que ser respeitado um limite.

Não é por exercer uma profissão que faz com que milhares de pessoas se tornem admiradores e consumidores do seu trabalho que esses indivíduos abrem mão de um direito que é, por definição, indisponível. Não querer que todos saibam de fatos em nada relacionados com os aspectos públicos de sua carreira e, indo além, não permitir que terceiros lucrem com a divulgação desses fatos, não pode ser confundido com censura, em sua conotação negativa.

Sim, seguindo Adriana Calcanhotto, vamos comer Caetano, desfrutá-lo, devorá-lo e mastigá-lo57; mas façamo-lo com parcimônia. Afinal, os biógrafos que nos perdoem, mas segredo é fundamental.

\section{REFERÊNCIAS}

ARENDT, Hannah. A condição humana. Tradução de Roberto Raposo. 10.ed. Rio de Janeiro: Forense Universitária, 2005.

BAUMAN, Zygmunt. Vigilância líquida: diálogos com David Lyon. Tradução de Carlos Alberto Medeiros. Rio de Janeiro: Jorge Zahar Editor, 2014.

BRASIL. Projeto de Lei n. 393 de 2011. Dispõe sobre a alteração do art. 20 da Lei no 10.406, de 10 de janeiro de 2002 - Código Civil, para ampliar a liberdade de expressão, informação e acesso à cultura. Autoria de Newton Lima. Brasília, DF: Câmara dos Deputados, 2011. Disponível em: <http://www.camara.gov.br/proposicoesWeb/prop_mostrarintegra?cod teor $=840265 \&$ filename $=P L+393 / 2011>$. Acesso em: 28 maio 2015.

BRASIL. Projeto de Lei da Câmara n. 42 de 2014. Altera o art. 20 da Lei no 10.406, de 10 de janeiro de 2002 - Código Civil, para garantir a liberdade de expressão, informação e o acesso à cultura. Brasília, DF: Senado Federal, 2014.

BRASIL. Supremo Tribunal Federal. Ação Direta de Inconstitucionalidade $\mathbf{n}^{\circ}$ 4815. Relatora: 57 Trecho da música "Vamos comer Caetano", de Adriana Calcanhotto. 
Ministra Carmem Lúcia Antunes Rocha. Origem Distrito Federal. DJe 16.02.2016. Disponível em: http://www.stf.jus.br/portal/processo/verProcessoAndamento.asp?incidente $=4271057$. Acesso em: 25.04.2016.

CABRAL, Marcelo Malizia. A colisão entre os direitos de personalidade e o direito de informação. In: FRUET, Gustavo Bonato; MIRANDA, Jorge; RODRIGUES JUNIOR, Otavio Luiz (Org.). Direitos da personalidade. São Paulo: Atlas, 2012.

CELLA, José Renato Gaziero; ROSA, Luana Aparecida do Santos. Controle social e necessidade de proteção de dados pessoais. In: Revista de Direito Brasileira (RBD). Florianópolis: CONPEDI, 2013, p.216-231.

DONEDA, Danilo. Considerações iniciais sobre os bancos de dados informatizados e o direito à privacidade. 2000. Disponível em: <http://www.estig.ipbeja.pt/ ac_direito/ Consideracoes.pdf>. Acesso em 28 maio 2015.

DONEDA, Danilo. Privacidade, vida privada e intimidade no ordenamento jurídico brasileiro: Da emergência de uma revisão conceitual e da tutela de dados pessoais. 2008. Disponível em: <http://www.ambitojuridico. com.br/site/index.php?n_link=revista_artigos_ leitura\&artigo_id=2460 >. Acesso em: 03 maio 2015.

GRAGNANI, Juliana. Gil e Caetano se juntam a Roberto Carlos contra biografias não autorizadas. Folha de São Paulo. Disponível em: < http://www1.folha.uol.com.br/ilustrada/2013/10/1352167gil-e-caetano-se-juntam-a-roberto-carlos-contra-biografias-nao-autorizadas.shtml>. Acesso em: 28 maio 2015a.

GRAGNANI, Juliana. Grupo que tentou modificar a Lei Áurea quer manter censura a biografias. Folha de São Paulo. Disponível em: < http://www1.folha.uol.com.br/ ilustrada/2013/11/1373580grupo-que-tentou-modificar-lei-aurea-quer-manter-censura-a-biografias.shtml>. Acesso em 28 maio 2015b.

GREENWALD, Gleen. Sem lugar para se esconder. Tradução de Fernanda Abreu. Rio de Janeiro: Sextante, 2014.

HOUAISS, Antônio. Grande dicionário Houaiss da língua portuuesa. Disponívem em: <http://houaiss.uol.com.br/>. Acesso em: 23 jun. 2015.

LAFER, Celso. A reconstrução dos direitos humanos: um diálogo com o pensamento de Hannah Arendt. São Paulo: Companhia das Letras, 1988. 
MAZUR, Maurício. A dicotomia entre os direitos de personalidade e os direitos fundamentais. In: FRUET, Gustavo Bonato; MIRANDA, Jorge; RODRIGUES JUNIOR, Otavio Luiz (Org.). Direitos da personalidade. São Paulo: Atlas, 2012.

ORWELL, George. 1984. Tradução de Wilson Velloso. 12. ed. São Paulo: Companhia das Letras, 1979.

RODRIGUES JUNIOR, Otavio Luiz. Do príncipe Bismarck à princesa Carolina de Mônaco: vida privada de pessoas célebres e as liberdades comunicativas no direito civil. In: CASSETTARI, Christiano (Org.). 10 anos de vigência do código civil brasileiro de 2002: estudos em homenagem ao professor Carlos Alberto Dabus Maluf. São Paulo: Saraiva, 2013.

SCHREIBER, Anderson. Direitos da personalidade. 2. ed. São Paulo: Atlas, 2013.

TEIXEIRA, Jerônimo. Página infeliz da nossa história: Gilberto Gil, Roberto Carlos, Chico Buarque e Caetano Veloso dizem que querem resguardar a privacidade - mas as propostas do grupo resumem-se a apenas uma infame palavra: censura. Revista Veja, São Paulo, p.8287, 23 de outubro de 2013.

Recebido em: set/2015 Aprovado em: set/2015 